The University of Maine

\title{
DigitalCommons@UMaine
}

Publications

Senator George J. Mitchell Center for Sustainability

Solutions

7-2009

\section{Thresholds and the Mismatch between Environmental Laws and Ecosystems}

\author{
Malcolm L. Hunter Jr. \\ University of Maine, mhunter@maine.edu \\ Michael J. Bean \\ Environmental Defense Fund \\ David Lindenmayer \\ The Australian National University \\ David S. Wilcove \\ Princeton University
}

Follow this and additional works at: https://digitalcommons.library.umaine.edu/ mitchellcenter_pubs

Part of the Ecology and Evolutionary Biology Commons, and the Environmental Law Commons

\section{Repository Citation}

Hunter Jr., Malcolm L.; Bean, Michael J.; Lindenmayer, David; and Wilcove, David S., "Thresholds and the Mismatch between Environmental Laws and Ecosystems" (2009). Publications. 37.

https://digitalcommons.library.umaine.edu/mitchellcenter_pubs/37 


\section{Thresholds and the Mismatch between Environmental Laws and Ecosystems}

MALCOLM L. HUNTER JR.,* MICHAEL J. BEAN,† DAVID B. LINDENMAYER, ‡ AND DAVID S. WILCOVE§

* Department of Wildlife Ecology, University of Maine, Orono, ME 04469, U.S.A., email hunter@umenfa.maine.edu

† Environmental Defense Fund, 1875 Connecticut Avenue, NW, Washington, D.C. 20009, U.S.A.

¥ Fenner School of Environment and Society, The Australian National University, Canberra, ACT 0200, Australia

$\S$ Woodrow Wilson School of Public and International Affairs, Princeton University, Princeton, NJ 08544, U.S.A. 
Most environmental laws define a threshold between legal and illegal and thus could be very effective if ecosystems were widely characterized by ecological thresholds. For example, if the integrity of a stream ecosystem drops precipitously when the concentration of a contaminant exceeds $50 \mathrm{ppm}$, then it would be efficient to have a law that prohibits contamination above this level. Conversely, if the ecological impacts of a perturbation increase linearly across a wide range - an ecological continuum - then any particular regulatory limit creates an arbitrary threshold that is not well matched to the actual ecological impact. If the ecological impact at $55 \mathrm{ppm}$ is only $20 \%$ greater than that at $45 \mathrm{ppm}$, is it logical to select $50 \mathrm{ppm}$ as a legal threshold? If modest environmental impacts occur at 30 or 40 ppm, does it make sense to begin regulation only at 50 ppm? Given the imperfect relationship between legal and ecological thresholds, we argue that increased emphasis on positive incentives, as an addition to threshold-based laws, would result in environmental management that is more attuned to the structure and function of ecosystems.

Ecologists have long sought to understand ecological thresholds, defined here as the point at which an abrupt change in ecosystem condition can occur (Bestelmeyer 2006; Briske et al. 2006; Groffman et al. 2006). These points may be defined by an event (e.g., a landslide dumping tons of sediment into a stream) or by a small change in an ecological driver that generates large responses (e.g., when a contaminant reaches a lethal level for a dominant or keystone species, thereby sharply reducing that species' population and profoundly altering the overall ecosystem). Some ecological thresholds are natural (e.g., when a river overflows its banks and floods adjacent floodplains), but applied ecologists and environmental managers are primarily concerned with human activities that may push ecosystems beyond thresholds (Walker \& Salt 2006). This is particularly true because crossing a threshold can shift an ecosystem into an alternative stable state from which it will not readily return to its original condition (May 1977; Scheffer \& Carpenter 2003; Zhang et al. 2003). For example, coral reefs can shift into a persistent alternative state dominated by macroalgae if key herbivore populations decline below a threshold (Mumby et al. 2007). 
Ecological thresholds occur in many ecosystems and can have important effects that are of concern to environmental managers (Scheffer et al. 2001; Folke et al. 2004; Groffman et al. 2006). Unfortunately, ecological thresholds tend to be discovered retroactively, and will probably continue to be a challenge to predict, in part because they vary spatially and temporally (Groffman et al. 2006; Carpenter et al. 2008).

Environmental laws (including both statutes enacted by legislative bodies and regulations enacted by government agencies) are not unique in creating legal thresholds. For example, in most countries, only people 18 years of age and above are permitted to vote, notwithstanding the fact that some 17-year-olds are capable of making informed electoral decisions and some 19-yearolds are not. This is done, in part, because laws strive for clarity, predictability, and uniformity to ensure that they are fair and practical to enforce.

In a perfect world regulatory thresholds would correspond to clear ecological thresholds, but in practice, this is difficult to achieve because ecosystems are highly variable. For example, the relationship between the loss of riparian vegetation and the deterioration of a riverine ecosystem varies among rivers depending on, for example, soils and slopes; thus, deciding how wide a protected riparian buffer zone should be is challenging. The ultimate decision typically reflects two different processes. First, a scientific assessment (probably based on data from a small portion of the affected ecosystems combined with some professional judgment) generates a recommendation, such as a specific number (e.g., $30 \mathrm{~m}$ ) or a modest range of numbers. Second, a political process unfolds in which this number is pushed up or down by competing interests and eventually results in a compromise that leads to the establishment of a threshold between legal and illegal. Hopefully this compromise lies on the safe side of any ecological thresholds that may exist, or in the absence of ecological thresholds, one hopes the compromise number is relatively low in the continuum of increasing impacts. Over time a regulatory threshold can be changed as more data are 
gathered, as technology changes, or as political winds shift, but in practice, once the numbers are chosen, they are likely to have considerable inertia.

Conceptually, environmental laws do not have to be based on simple, polar distinctions; they could be designed around an ecological continuum. For example, a riparian management law could allow no removal of native vegetation within $10 \mathrm{~m}$ of the shore, $10 \%$ removal from 10 to $20 \mathrm{~m}$ of the shore, and $20 \%$ from 20 to $30 \mathrm{~m}$ of the shore. Nevertheless, such complicated laws would be difficult to legislate and enforce. The laws that come closest to this are those that, in effect, recognize a series of thresholds. For example, some riparian management laws recognize a set of different buffer widths depending on the type of human disturbance (e.g., clearing native vegetation is prohibited within $20 \mathrm{~m}$ of the shore, no buildings are allowed within $30 \mathrm{~m}$, no mining is allowed within $50 \mathrm{~m}$; Ekness \& Randhir 2007).

It is unfortunate that developing and enforcing environmental laws based on ecological continua is complicated because ecosystems are probably characterized by more ecological continua than ecological thresholds (Hunter \& White 1997; Lindenmayer et al. 2005). For example, researchers in Australia were unable to identify threshold patterns for relationships between the amount of vegetation cover and various metrics of species richness and abundance for invertebrates (Parker \& Mac Nally 2002), reptiles, and birds (Lindenmayer et al. 2005). Even if some of the key drivers of ecosystem integrity exhibit threshold responses, ecosystems are probably characterized by numerous ecological continua that merit attention from ecosystem managers, especially if one considers an ecosystem's entire suite of species and environmental parameters.

Although laws that create legal thresholds are a good response to environmental impacts characterized by ecological thresholds, we need additional environmental management tools more attuned to the reality that ecological continua are common. New prohibitions designed Ecological Thresholds and Environmental Laws around ecological continua are probably not the answer because they are likely to be too complicated 
to legislate and enforce. We see a need to develop and promote voluntary environmental safeguards that complement (but do not replace) existing laws by going beyond regulatory thresholds. Consider a nation that has a law to protect native vegetation in 30-m-wide riparian buffer zones because it has been determined that buffers of this width avoid an ecological threshold based on excessive sedimentation and a profound loss of water quality. If riparian zones were expanded to 40 or $50 \mathrm{~m}$, many of the societal values associated with riparian zones-esthetics, recreational opportunities, a diverse and abundant biota, and more-would be enhanced, roughly commensurate with the increase in the width of the riparian zone. Furthermore, wider buffers would also offer some insurance against the possibility that the buffers based on a sedimentation risk threshold might not be wide enough to perform adequately under unusual circumstances (e.g., torrential rains in a watershed with extremely steep slopes) or mitigate other problems such as pesticide drift from spraying in adjacent cropland. We are not aware of an incentive program structured around a discrete ecological continuum, but the Conservation Reserve Program of the United States Department of Agriculture approximates this idea in its use of an "environmental benefit index" to select lands eligible for an incentive program on the basis of multiple ecological criteria such as benefits to water quality, air quality, and wildlife (Ruhl et al. 2007).

Various mechanisms exist for encouraging people to do more for the environment than meet legal minima, including financial incentives (e.g., direct payments or tax relief), public recognition (e.g., good stewardship awards presented by governments or environmental groups), and recognition that carries with it potential financial benefits (e.g., green certification) (Stewart 2001). A key question is how such incentives can be efficiently structured to reflect ecological continua. This is straightforward when financial rewards are used because the amount of compensation can be directly tied to the extent to which one goes above and beyond the minimum requirements set by law. For example, if a landowner maintains $40-\mathrm{m}$ buffers instead of the 30-m buffers mandated by law, thereby resulting in a total of 7,000 ha of additional riparian buffer, and if these buffers are valued at $\$ 2 \cdot \mathrm{ha}^{-1} \cdot \mathrm{year}^{-1}$ in tax relief, then the landowner's annual tax bill 
could be relieved by $\$ 14,000$. Such a program would require a process for determining where the "law of diminishing returns" sets in because it might not be cost-effective to offer compensation for 70-or 80-m buffer zones. This issue could be addressed through the same interaction of science and politics that generates legal thresholds, the 30-m minimum in this case. There is some danger of such incentives generating perverse incentives (also known as creating a moral hazard) if they compel landowners who are voluntarily exceeding minimum standards to demand payment for the ecosystem services they are providing (Salzman 2006).

Another avenue for encouraging environmental activity that exceeds minimum standards involves trading schemes (e.g., acid-rain emission reduction credits and carbon credits). These systems allow regulated parties to sell their "excess compliance" to other regulated parties that cannot meet required standards as cheaply. To the extent that unregulated interests (e.g., conservation organizations or governments) are willing to buy and retire credits (rather than let them be used to avoid required compliance), the result is an incentive to achieve aggregate environmental action beyond the required threshold and reward those who do the most, which should spur innovation (Stewart 2001).

In conclusion, environmental laws that generate regulatory thresholds have two roles: assuring that particular ecological thresholds are not exceeded and preventing ecosystems from being pushed toward the high-impact end of ecological continua. Promoting positive incentives that are additive to threshold-based laws could more fully address ecological continua by encouraging environmental activities that bring commensurate increases in ecological benefits and go well beyond regulatory minima. 


\section{Acknowledgment}

Maine Agricultural and Forest Experiment Station Publication number 3040.

\section{Literature Cited}

Bestelmeyer, B. T. 2006. Threshold concepts and their use in rangeland management and restoration: the good, the bad, and the insidious. Restoration Ecology 14:325-329.

Briske, D. D., S. D. Fuhlendorf, and F. E. Smeins. 2006. A unified framework for assessment and application of ecological thresholds. Rangeland Ecology and Management 59:225-236.

Carpenter, S. R., et al. 2008. Leading indicators of trophic cascades. Ecology Letters 11:128-138.

Ekness, P., and T. Randhir. 2007. Effects of riparian areas, stream order, and land use disturbance on watershed-scale habitat potential: an ecohydrologic approach to policy. Journal of the American Water Resources Association 43:1468-1482.

Folke, C, S. Carpenter, B. Walker, M. Scheffer, T. Elmqvist, L. Gunderson, and C. S. Holling. 2004. Regime shifts, resilience, and biodiversity in ecosystem management. Annual Review of Ecology Evolution and Systematics 35:557-581.

Groffman, P., et al. 2006. Ecological thresholds: the key to successful environmental management or an important concept with no practical application? Ecosystems 9:1-13.

Hunter, M. L., Jr., and A. White. 1997. Ecological thresholds and the definition of old-growth forests. Natural Areas Journal 17:292-296.

Lindenmayer, D. B., J. Fischer, and R. B. Cunningham. 2005. Native vegetation cover thresholds associated with species responses. Biological Conservation 124:311-316.

May, R. M. 1977. Thresholds and breakpoints in ecosystems with a multiplicity of stable states. Nature 269:471-477.

Mumby, P. J., A. Hastings, and H. J. Edwards. 2007. Thresholds and the resilience of Caribbean coral reefs. Nature 450:98-101.

Parker, M., and R. Mac Nally. 2002. Habitat loss and the habitat fragmentation threshold: an experimental evaluation of impacts on richness and total abundances using grassland invertebrates. Biological Conservation 105:217-229.

Ruhl, J. B., S. E. Kraft, and C. L. Lant. 2007. The law and policy of ecosystem services. Island Press, Washington, D.C.

Salzman, J. 2006. A field of green? The past and future of ecosystem services. Journal of Land Use and Environmental Law 21:133-151.

Scheffer, M., and S. R. Carpenter. 2003. Catastrophic regime shifts in ecosystems: linking theory to observation. Trends in Ecology \& Evolution 18:648-656. 
Scheffer, M., S. Carpenter, J. A. Foley, C. Folke, and B. Walker. 2001. Catastrophic shifts in ecosystems. Nature 413:591-596.

Stewart, RB. 2001. A new generation of environmental regulation? Capital University Law Review 29:21-182.

Walker, B., and D. Salt. 2006. Resilience thinking: sustaining ecosystems and people in a changing world. Island Press, Washington, D.C.

Zhang, J., J. Jorgensen, S. E. Beklioglu, and M. Ince. 2003. Hysteresis in vegetation shift-Lake Mogan prognoses. Ecological Modelling 164:227-238. 